\title{
CONTROLE DO AMADURECIMENTO DO KIWI CV. MONTY COM 1-METILCICLOPROPENO'
}

\author{
JULIUS BLUM² \& RICARDO ANTONIO AYUB ${ }^{3}$
}

RESUMO-O 1-metilciclopropeno (1-MCP) é um gás que atua inibindo o sítio de ação do etileno, aumentando o tempo de armazenamento de frutos. O objetivo deste trabalho foi avaliar o efeito deste gás na conservação pós-colheita de kiwi 'Monty', à temperatura ambiente. Ele consistiu na exposição dos frutos a concentrações de 0; 0,5 e 1,0 $\mathrm{mg} \mathrm{dm}^{-3}$ de 1-MCP, durante 24 horas, e posterior estocagem a $20 \pm 4{ }^{\circ} \mathrm{C}$, por até 20 dias, com avaliações a cada 4 dias. Avaliaram-se: firmeza, translucidez da polpa, sólidos solúveis ( $\mathrm{SS}$ ), $\mathrm{pH}$, acidez titulável (AT), pectina, \% de frutos firmes para transporte e consumo. A translucidez da polpa mostrou-se um parâmetro adequado para monitoramento do amadurecimento, visto que houve correlação com a firmeza. A aplicação de 1-MCP preservou a firmeza e preveniu a translucidez da polpa, prolongando a qualidade para transporte e consumo por 4 e 12 dias, respectivamente, e não teve efeito sobre o pH, SS e pectinas. Nos tratamentos com 1-MCP, ocorreu um aumento inicial na acidez, mas com o passar do tempo, ocorreu diminuição da mesma, da firmeza e aumento dos sólidos solúveis e da translucidez da polpa, caracterizando o amadurecimento dos frutos.

Termos para indexação: pós-colheita, Actinidia deliciosa, armazenamento.

\section{THE USE OF 1-METHYLCYCLOPROPENE IN RIPENING CONTROL OF KIWI CV. MONTY}

\begin{abstract}
The gas 1-methylcyclopropene acts inhibiting the action site of ethylene, increasing the postharvest period of the fruits. The aim of this work was to evaluate the effect of this gas on postharvest conservation of kiwifruit cv. Monty at ambient temperature. The study consisted of fruit exposition to 1$\mathrm{MCP}$ at the concentrations of $0,0,5$ and $1,0 \mathrm{mg} \mathrm{dm}^{-3}$ during 24 hours, and stored at $20 \pm 4^{\circ} \mathrm{C}$ per 20 days, with evaluations at 4 days intervals. It had been evaluated: firmness of pulp, pulp color, soluble solids, $\mathrm{pH}$, total acidity, $\%$ of pectin and $\%$ of firm fruits for transport and consumption. The color of pulp was an adequate parameter to evaluate the ripening of fruits, since it had correlation with the firmness. The application of 1MCP preserved the firmness the color of the pulp, extending the quality for transportation and consumption for 4 and 12 days, and did not have effect on $\mathrm{pH}$, soluble solids and pectin. In the treatments with 1-MCP occurred an initial increase of the acidity with posterior decrease. With time a reduction of the firmness, an increase of the soluble solids and the color of the pulp occurred, characterizing the ripening of the fruits. Index terms: post harvest, Actinidia deliciosa, storage.
\end{abstract}

\section{INTRODUÇÃO}

O controle do amadurecimento é o pontochave na conservação de frutos, visando à sua posterior comercialização. Entretanto, a qualidade dos mesmos depende do estádio adequado de maturação, que, no caso de frutos climatéricos, está associada ao aumento na produção de etileno.

O kiwi apresenta alta sensibilidade póscolheita ao etileno (Warrington \& Weston, 1990), causando-lhe rápido amolecimento (Neves et al.,
2003), e em geral respondem à concentração de 0,1 $\mu L . L^{-1}$ na atmosfera de armazenagem, com redução em sua conservação (Sisler \& Serek, 1997). Este hormônio liga-se às moléculas receptoras, provavelmente proteínas membranares, ativando o amadurecimento (Golding et al., 1998).

O 1-metilciclopropeno (1-MCP) é um produto que atua inibindo temporariamente a ação do etileno, pela sua interação com o sítio receptor do etileno por longo período (Sisler \& Serek, 1997), prevenindo a formação de complexos ativos relacionados à ação

\footnotetext{
${ }^{1}$ (Trabalho 122-03). Recebido em: 16-05-2008. Aceito para publicação em: 24-10-2008.

${ }^{2}$ Eng. Agron., MSc, Universidade Estadual de Ponta Grossa (UEPG), 84030-900 Ponta Grossa-PR. E-mail: juliusblum@yahoo.com.br

${ }^{3}$ Eng. Agron., Prof. Dr. do Departamento de Fitotecnia e fitossanidade, UEPG, Av. Carlos Cavalcante, 4748, Setor de Ciências Agrárias e Tecnologia, Departamento de Fitotecnia e Fitossanidade, 84030-900 Ponta Grossa-PR. E-mail: rayub@uepg.br
} 
do etileno (Watkins 2002; Binder \& Bleecker, 2003) e o amadurecimento do fruto (Pinheiro et al., 2007). Ele é importante para o manejo pós-colheita de frutas climatéricas (Argenta et al., 2001), com relatos na literatura do seu uso com sucesso no armazenamento de kiwi cv. Bruno (Neves et al., 2003), banana-maçã (Pinheiro et al., 2007), maçã Royal gala (Corrent et al., 2004), caqui cv. Fuyu (Krammes et al., 2006) e sapoti (Morais et al., 2006). Entretanto, as respostas à aplicação são variáveis com a espécie, cultivar, região e sistema de manejo de colheita e armazenagem (Watkins et al., 2000).

O objetivo deste trabalho foi avaliar a conservação pós-colheita do kiwi cv. Monty com o uso do 1-metilciclopropano à temperatura ambiente.

\section{MATERIAL E MÉTODOS}

Frutos de kiwi cv. Monty colhidos no dia 15 de maio de 2007, em pomar comercial, foram levados ao laboratório para a aplicação dos tratamentos com 1-MCP, no dia 16 de maio de 2007.

Os tratamentos consistiram na exposição dos frutos, por $24 \mathrm{~h}$, a concentrações de $0 ; 0,5$ e $1,0 \mathrm{mg}$ $\mathrm{dm}^{-3}$ de 1-MCP. O gás foi gerado pela diluição do produto comercial $\mathrm{Smartfresh}^{\mathrm{SM}}$ em água, à temperatura ambiente, e bombeado através de um sistema fechado para a câmara onde se encontravam os frutos.

Foram realizadas avaliações de: firmeza de polpa com penetrômetro com ponteira de $8 \mathrm{~mm}$, em dois pontos da zona equatorial dos frutos; translucidez da polpa, sendo 1 (translúcido em torno da semente), 2 (metade da polpa translúcida) e 3 (polpa translúcida); teor de sólidos solúveis (SS), determinados por refratometria em ${ }^{\circ} \mathrm{Brix}$; acidez por titulação com $\mathrm{NaOH}$ e resultado expresso em $\%$ de ácido cítrico; $\mathrm{pH}$; teor de pectina da fruta pelo método de McCready \& McComb (1952) e porcentagem de frutos firmes, considerando a firmeza mínima aceitável para transporte de $36 \mathrm{~N}$ e para consumo de $5 \mathrm{~N}$ (Legarraga, 1994).

O delineamento experimental foi o fatorial com 3 concentrações de 1-MCP x 5 tempos de avaliação, ou seja, $4 ; 8 ; 12 ; 16$ e 20 dias após a aplicação. Para a translucidez da polpa e a firmeza, foram avaliados 16 frutos, em que cada fruto foi considerado uma repetição. As demais determinações foram realizadas em amostras compostas de 4 frutos, com 4 repetições.

Os tratamentos com 1-MCP foram comparadas pelo teste de Tukey, e a vida de prateleira, analisada através de regressão polinomial, sendo consideradas as regressões com probabilidade de erro menor ou igual a $5 \%$.

\section{RESULTADOS E DISCUSSÃO}

A firmeza da polpa e a concentração de sólidos solúveis são as características dos frutos mais importantes no monitoramento da maturação (Merino \& Uriarte, 1989; Saquet \& Brackmann, 1995). Neste trabalho, além destes critérios, usamos uma escala de translucidez da polpa. Este parâmetro mostrou-se eficiente, visto que ocorreu correlação significativa com a firmeza da polpa, sendo que quanto mais translúcida a polpa menor é a firmeza (Figura 1).

O tratamento com 1-MCP retardou o amadurecimento, pois os frutos não tratados apresentavam polpa com maior translucidez e menor firmeza de polpa durante o armazenamento que os frutos tratados (Tabela 1). Esses resultados estão de acordo com os obtidos por Kim et al. (2000) e Waclawovsky et al. (2001), que trabalharam com a aplicação de 1-MCP em frutos de Kiwi armazenados a 0 e $20^{\circ} \mathrm{C}$ e Neves et al. (2003), que trabalharam em atmosfera modificada.

Cabe ressaltar que a análise inicial caracterizou o lote de frutos com um teor de SS de 9,5 ${ }^{\circ}$ Brix, bastante elevado para frutos a serem armazenados (Legarraga, 1994), e ainda assim o 1MCP mostrou-se capaz de aumentar o tempo de armazenamento dos frutos.

A aplicação de 1-MCP não provocou alterações nos valores de $\mathrm{pH}$ e teor de pectina (Tabela 1). Embora fosse esperado que os teores de pectina sofressem alterações com o decréscimo da firmeza, isto não ocorreu, provavelmente devido ao método utilizado para determinar a concentração de pectina ter sido capaz de quantificar também os produtos da degradação da mesma, como, por exemplo, o ácido galacturônico.

Com o prolongamento da armazenagem, houve aumento da translucidez da polpa, que foi acompanhado pelo aumento natural dos SS e perda de firmeza (Figura 2), caracterizando o amadurecimento dos frutos, como também observado por Neves et al. (2003), com elevação no teor de SS alcançando $15{ }^{\circ}$ Brix ao longo do armazenamento de kiwi cv. Bruno, em atmosfera modificada, mais aplicação de 1-MCP.

Uma avaliação tão importante quanto a firmeza média dos frutos é o percentual de frutos firmes, pois este resultado dará com precisão o número de frutos que serão descartados durante o transporte ou comercialização. Conforme Legarraga (1994), para o consumo do fruto, o ideal é que a firmeza esteja acima de $5 \mathrm{~N}$; no entanto, para o transporte e comercialização sem que ocorram danos, 
o ideal é que os frutos apresentem mais de $36 \mathrm{~N}$ de firmeza. Deste modo, avaliou-se o percentual de frutos passíveis de transporte e comercialização (mais de $36 \mathrm{~N}$ ), e passíveis de consumo (mais de 5 N).

Os frutos sem tratamento com 1-MCP perderam a firmeza rapidamente, sendo que apenas $62 \%$ dos frutos estariam em condições de ser transportados após quatro dias de armazenamento e apenas $72 \%$ estariam em condições de ser consumidos após 8 dias de armazenagem (Tabela 2). Nos frutos tratados com 0,5 e $1,0 \mathrm{mg} \mathrm{dm}^{-3}$ de 1 MCP, 97 e 81\%, respectivamente, estariam em condições de ser transportados aos 4 dias, e mesmo após 16 dias de armazenamento, aproximadamente 90\% dos frutos estariam em condições de ser consumidos. Portanto, a aplicação de 1-MCP prolongou as condições de transporte dos frutos de kiwi por 4 dias, e as condições de consumo, por pelo menos 12 dias.
Embora tenha ocorrido correlação entre o pH e a acidez do fruto (Figura 1), o efeito do tempo foi diferenciado para estas características. $\mathrm{O} \mathrm{pH}$ da fruta não variou com o tempo (Figura 2). Porém houve interação entre os tratamentos de 1-MCP com o tempo para a acidez, ocorrendo aumento inicial da acidez e posterior decréscimo (dados não apresentados), devido ao acúmulo de ácidos orgânicos que não se degradaram em função de o 1-MCP ter segurado a maturação dos frutos. Já Neves et al. (2003) e Waclawovsky et al. (2001) relataram a diminuição da acidez titulável do fruto de kiwi armazenado tratado com 1-MCP. Esta diferença é devida ao maior período de armazenagem avaliado pelos mesmos, já que se tratava de armazenagem frigorificada.
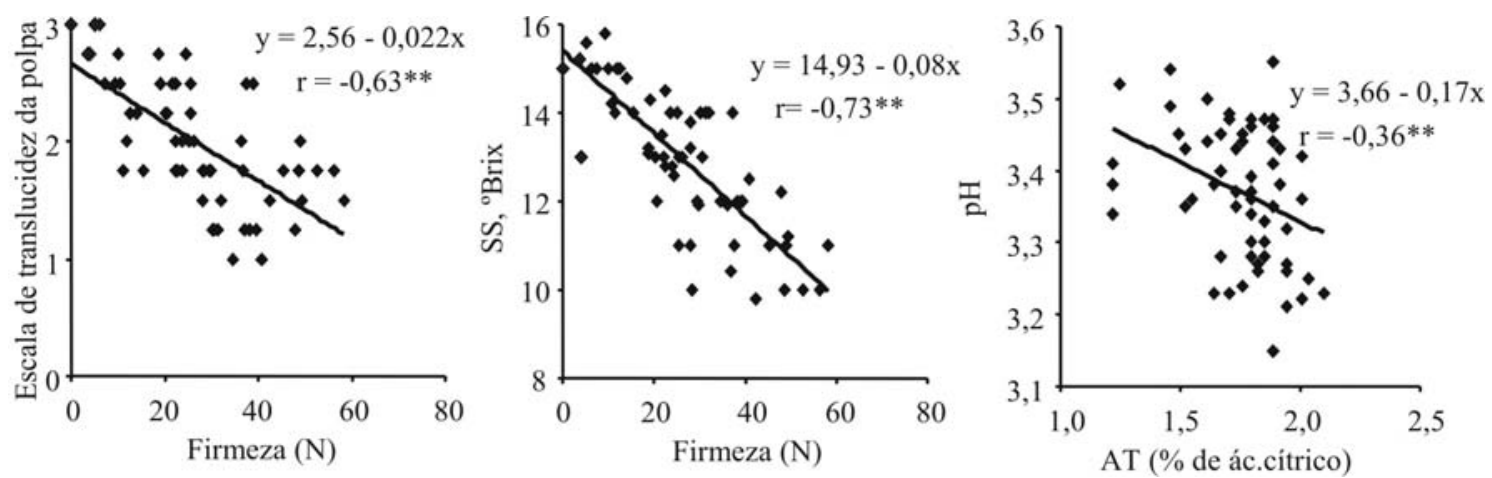

FIGURA 1- Correlações entre características físicas e químicas da polpa do kiwi.
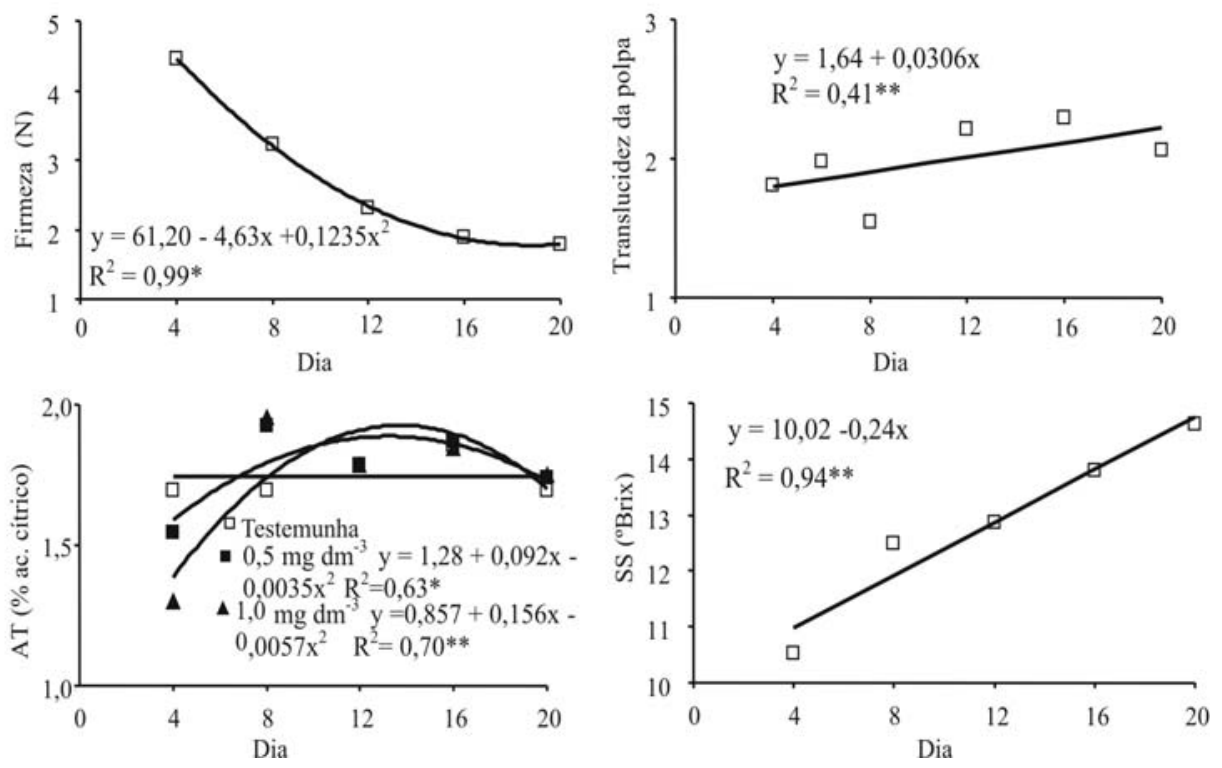

FIGURA 2 - Evolução da firmeza, translucidez da polpa, acidez titulável e sólidos solúveis do fruto de kiwi 'Monty' em função do tempo de armazenagem à temperatura ambiente. 
TABELA 1- Avaliação da translucidez da polpa, firmeza, pH, teor de pectina, sólidos solúveis (SS) e porcentagem de frutos firmes de kiwi 'Monty' tratados com 1-MCP. Ponta Grossa-PR, 2007.

\begin{tabular}{|c|c|c|c|c|c|}
\hline Tratamento & $\begin{array}{c}\text { Translucidez da } \\
\text { polpa }\end{array}$ & Firmeza $(\mathrm{N})^{1}$ & $\mathrm{pH}$ & Pectina $(\%)$ & $\mathrm{SS}\left({ }^{\circ}\right.$ Brix $)$ \\
\hline $0 \mathrm{mg} \mathrm{dm}^{-3}$ & $2,3 \mathrm{a}$ & $21,76 \mathrm{~b}$ & 3,39 & 0,28 & 13,14 \\
\hline $0,5 \mathrm{mg} \mathrm{dm}^{-3}$ & $1,8 \mathrm{~b}$ & $32,42 \mathrm{a}$ & 3,36 & 0,25 & 12,51 \\
\hline $1,0 \mathrm{mg} \mathrm{dm}^{-3}$ & $1,9 \mathrm{~b}$ & $27,83 \mathrm{ab}$ & 3,36 & 0,24 & 12,93 \\
\hline CV (\%) & $21,3 * *$ & $36,37 * *$ & $2,06^{\mathrm{ns}}$ & $23,98^{\mathrm{ns}}$ & $7,16^{\mathrm{ns}}$ \\
\hline
\end{tabular}

* Médias seguidas da mesma letra não diferem entre si, pelo teste de Tukey, a $5 \%$ de probabilidade. ${ }^{1} \%$ de frutos com firmeza acima de $20 \mathrm{~N}$.

TABELA 2- Percentual de frutos com firmeza superior a 5 e $36 \mathrm{~N}$ após armazenamento a temperatura ambiente.

\begin{tabular}{lccc}
\hline & \multicolumn{3}{c}{$1-\mathrm{MCP}\left(\mathrm{mg} \mathrm{dm}^{-3}\right)$} \\
Tempo (dias) & 0 & 0,5 & 1,0 \\
\hline & & $\%$ de frutos com mais de $36 \mathrm{~N}$ & \\
8 & $62,5 \mathrm{Ca}$ & $96,9 \mathrm{Aa}$ & $81,3 \mathrm{Ba}$ \\
12 & $37,5 \mathrm{Ab}$ & $43,8 \mathrm{Ab}$ & $37,5 \mathrm{Ab}$ \\
16 & $34,4 \mathrm{Ab}$ & $31,2 \mathrm{Abc}$ & $3,1 \mathrm{Bc}$ \\
20 & $0 \mathrm{Bc}$ & $15,6 \mathrm{Ac}$ & $9,4 \mathrm{ABc}$ \\
$\mathrm{CV}(\%)$ & $0 \mathrm{Bc}$ & $15,6 \mathrm{Ac}$ & $6,3 \mathrm{ABc}$ \\
\hline & & 50,8 & \\
\hline 4 & & $100 \mathrm{Aa}$ & $100 \mathrm{Aa}$ \\
8 & $90,6 \mathrm{Aa}$ & $100 \mathrm{Aa}$ & $90,6 \mathrm{Aa}$ \\
12 & $71,9 \mathrm{Bab}$ & $100 \mathrm{Aa}$ & $81,3 \mathrm{Aa}$ \\
16 & $62,5 \mathrm{Bb}$ & $90,6 \mathrm{Aa}$ & $68,8 \mathrm{Ab}$ \\
\hline $\mathrm{CV}(\%)$ & $56,3 \mathrm{Bb}$ & $78,1 \mathrm{Aa}$ & \\
\hline
\end{tabular}

Médias seguidas de uma mesma letra maiúscula na linha ou minúscula na coluna não diferem entre si, pelo teste de Tukey $\mathrm{p} \leq 0,05$.

\section{CONCLUSÕES}

1-O 1-MCP foi eficiente em retardar a maturação de kiwis cv. Monty pela manutenção da sua firmeza, caracterizada pela maior porcentagem de frutos firmes acima de 5 e $36 \mathrm{~N}$ e pela menor evolução da translucidez da polpa.

2-A concentração de $0,5 \mathrm{mg} \mathrm{dm}^{-3}$ de 1 -MCP é suficiente para a conservação dos frutos, por quatro dias para transporte e 12 dias para consumo.

\section{REFERÊNCIAS}

ARGENTA, L. C.; MATTHEIS, J.; FAN, X. Retardamento da maturação de maçãs 'Fuji ' pelo tratamento com 1-MCP e manejo da temperatura. Revista Brasileira de Fruticultura, Jaboticabal, v.23, n. 2, p. 270-273, 2001.

BINDER, B. M.; BLEECKER, A. B. A model for ethylene receptor function and 1-methycyclopropene action. Acta Horticulturae, Wageningen, v. 628, p. 177-187, 2003.
CORRENT, A. R.; PARUSSOLO, A.; GIRARDI, C. L.; ROMBALDI, C. V. Efeito do 1-metilciclopropeno na conservação de maçãs 'Royal Gala'em ar refrigerado e atmosfera controlada. Revista Brasileira de Fruticultura, Jaboticabal, v.26, n. 2, p. 217-221, 2004.

GOLDING, J. B.; SHEARER, D.; WYLLIE, S. G.; MCGLASSON, W. B. Application of 1-MCP and propylene to identify ethylene-dependent ripening processes in mature banana fruit. Postharvest Biology and Technology, Amsterdan, n. 14, p. 87-98, 1998.

KRAMMES, J. G.; ARGENTA, L. C.; Vieira, M. J. Influences of 1-methycyclopropene on quality of persimmon fruit cv. Fuyu after cold storage. Acta Horticulturae, Wageningen, v. 727, p. 513-518, 2006.

KIM, H. O.; HEWETTL, E. W.; LALLU, N. Softening and ethylene production of Kiwifruit reduced with 1-methylcyclopropene. In: INTERNATIONAL CONFERENCE ON POSTHARVEST SCIENCE POSTHARVEST, 4., 2000, Jerusalem. Abstracts... Jerusalem: ISHS, 2000. p. 21. 
LEGARRAGA, D. M. Cosecha, conservación y normas de embalaje de Kiwis. In: SIMPÓSIO BRASILEIRO DA CULTURA DO KIWI, 1., 1994, Farroupilha. Anais.... Bento Gonçalves: EMBRAPA/ CNPUV, 1994.p. 25-29, 1994.

McCREADY, R. M.; McCOMB, E. A. Extraction and determination of total pectic materials in fruits. Analyctical Chemistry, Oxford, v. 24, n.12, 1952.

MERINO, D.M.; URIATE, C. Conservación del kiwi. Fruticultura Professional, Barcelona, n.22, p.35-42, 1989.

MORAIS, P. L. D. de; LIMA, L. C. de O.; ALVES, R. E.; ALVES, J. D.; ALVES, A. de P. Amadurecimento de sapoti (Manilkara zapota L.) submetido ao 1metilciclopropeno. Revista Brasileira de Fruticultura, Jaboticabal, v.28, n. 3, p. 369-373, 2006.

NEVES, L. C.; CORRENT, A.; MARINI, L.; LUCCHETTA, L.; ZANUZO, M. R. ; GONÇALVES, E. D. ; ZANATTA, J. ; CANTILLANO, F. R.; ROMBALDI, C. V. Atmosfera modificada e 1metilciclopropeno na conservação pós-colheita de Kiwis cv. Bruno. Revista Brasileira de Fruticultura, Jaboticabal, v.25, n. 3, p. 390-393, 2003.

PINHEIRO, A. C. M.; VILAS BOAS, E. V. de B.; ALVES, A. de P.; La SELVA, M. Amadurecimento de bananas 'Maçã'submetidas ao 1-Metilciclopropeno (1-MCP). Revista Brasileira de Fruticultura, Jaboticabal, v.29, n. 1, p. 001-004, 2007.
SAQUET, A. A.; BRACKMANN, A. A cultura do kiwi. Ciência Rural, Santa Maria, v.25, n.1, p. 177182, 1995.

SISLER, E. C.; SEREK, M. Inhibitors of ethylene responses in plants at the receptor level: Recent developments. Plant Physiology, Copenhagen, v. 100, p. 577-582, 1997.

WACLAWOVSKY, A. J.; DONAZZOLO, J.; NEUWALD, D. A.; BRACKMANN, A. Qualidade pós-colheita de Kiwis (Actinidia deliciosa, Chevalier), cv. Bruno, tratados com 1metilciclopropeno (1-MCP). In: CONGRESSO BRASILEIRO DE FISIOLOGIA VEGETAL, 8., 2001, Ilhéus. Anais... Ilhéus: SBFV: Ilhéus, 2001. CD-ROM 4-030.

WARRINGTON, I. J.; WESTON, G. C. Kiwifruit science and management. Auckland: Ray Richards Publisher, 1990. 576p.

WATKINS, C. B. Ethylene synthesis, mode of action, consequences and control. In: KNEE, M. (Ed.). Fruit quality and its biological basis. Sheffield: Academic Press, 2002. p 180-224, 2002.

WATKINS, C. B.; NOCK, F. J.; WHITAKER, D. B. Response of early, mid and late season apple cultivars to postharvest application of 1-methylcyclopropene (1-MCP) under air and controlled atmosphere storage conditions. Postharvest Biology and Technology, Amsterdam, v. 19, p. 17-32, 2000. 